\title{
"Inspecionar, instruir e dirigir": a configuração da inspeção da instrução pública na província do Paraná (1854-1889)
}

\begin{abstract}
Resumo
Reestruturar a inspeção do ensino após a emancipação do Paraná como comarca da província de São Paulo foi a ação esperada pelo presidente da província, após a nomeação do primeiro Inspetor Geral, Jesuíno Marcondes de Oliveira e Sá, em 1854. Até então, a inspeção era feita por meio de comissões, formadas por três integrantes e que se reportavam à Inspetoria Paulista. Com a reorganização, a inspeção do ensino passou a ser feita pelo Inspetor Geral e por inspetores de distrito. Ao longo do período, novos cargos e funções foram agregados a essa estrutura, tais como: inspetores paroquiais/municipais, Conselhos de Instrução/Literários e a Superintendência do Ensino Obrigatório. O presente estudo tem como objetivo não somente identificar essa administração e sua função, como também localizar que usos e sentidos os responsáveis pela mesma davam para as suas ações frente às escolas, professores, alunos e sociedade no geral.
\end{abstract}

Palavras-chave: Inspeção da Instrução. Educação. Paraná. História.
Etienne Baldez Louzada Barbosa

Prefeitura Municipal de Nova Iguaçu-RJ/Brasil

blb_etienne@hotmail.com

\section{Para citar este artigo:}

BARBOSA, Etienne Baldez Louzada. "Inspecionar, instruir e dirigir": a configuração da inspeção da instrução pública na província do Paraná (1854-1889). Revista Linhas. Florianópolis, v. 18, n. 36, p. 152-177, jan./abr. 2017. 


\title{
"Inspect, instruct and direct": configuration of the public education inspection in the province of Paraná (1854-1889)
}

\begin{abstract}
The restructuring of the inspection of education, after the emancipation of Paraná as a district, from the province of São Paulo, was the action expected by the president of the province, next to the nomination of the first General Inspector, Jesuíno Marcondes de Oliveira e Sá, in 1854. Until then, the inspection was made by committees, composed by three members, who reported to the Paulista Inspectorate. With the reorganization, the inspection of education started to be made by the General Inspector and by district inspectors. Over the period, new positions and functions were added to this structure, such as: parochial/municipal inspectors, Instructional/Literary Councils and the Superintendence of Mandatory Education. The purpose of this study is not only to identify this administration and its function, but also to find out which uses and meanings those responsible for them gave to their own actions towards schools, teachers, students and society in general.
\end{abstract}

Keywords: Inspection of Education. Education. Paraná. History. 
(...) essa trama não se organiza, necessariamente, em uma sequência cronológica: como um drama interior, ela pode passar de um plano para

outro. (VEYNE, 1998, p. 42)

Escrever sobre a inspeção e seus sujeitos é perceber, na tessitura das ações da Inspetoria Geral da Instrução Pública, o modo como se estruturava a inspeção - seus cargos e funções - e os usos e sentidos dados pelos inspetores à sua prática. Dentro da conjuntura de organização da inspeção do ensino no Brasil, no século XIX, é possível apontarmos o Ato Adicional de 1834 (lei $n^{\circ}$ 16, de 12/08/1834) como uma legislação que, ao deixar a decisão das políticas de instrução pública ao cargo das províncias, de forma descentralizada do Poder Imperial, contribuiu para que as ações fossem desenvolvidas de acordo com o contexto e necessidades de cada região. No entanto, como pondera André Castanha (2006), a descentralização efetivada pelo Ato Adicional de 1834 não rompeu com ideias norteadoras para a instrução pública que se conectavam com a Corte, na província do Rio de Janeiro. Seguindo a análise da legislação de algumas províncias, o historiador aponta que "é possível perceber que havia uma filosofia, uma direção que orientava esse conjunto de leis, no que se refere à instrução elementar, ao controle do trabalho do professor, ao caráter moral, e ao projeto político e social para aquela região" (CASTANHA, 2006, p. 189).

Concordo com o autor que havia ideias e práticas semelhantes, principalmente quando nos voltamos para a legislação. Compartilho da perspectiva teórica adotada por Sanjay Subrahmanyam e Serge Gruzinski de que a rede de troca não é unilateral, de que as histórias estão conectadas e que, nesse sentido, o historiador não deve somente repensar sua noção de periodização, como também reelaborar suas "noções de fronteiras e circuitos, a redesenhar mapas que emergem das problemáticas que encaixem nas cartografias preexistentes" (SUBRAHMANYAM, 2012. p. 19). Como demonstra Serge Gruzinski (2003), o olhar deve se voltar para os processos de transformação, mas sem tomá-los como processos de subjugação, tentando entendê-los pelo viés das novas conexões e pela formulação de outras redes culturais (GRUZINSKI, 2003). 
No que concerne à função prescrita e às práticas da inspeção durante o Oitocentos, diferentes pesquisadores têm apontado a ação das Inspetorias/Diretorias Gerais da Instrução como tendo uma forte faceta atrelada à vigilância dos professores e alunos, seguida de punições aos mesmos ou sanções legais aos responsáveis que não enviassem as crianças às escolas. Pesquisadores da área de História da Educação têm investigado a organização, a função prescrita e as práticas da inspeção durante o Oitocentos, voltando muitas vezes suas análises para uma perspectiva da inspeção atrelada à vigilância, com ações passíveis de punições tanto de professores quanto de alunos. Uma análise que coaduna com o demonstrado por Michel Foucault (2008) quando escreve sobre os dispositivos de fiscalização e cumprimento dos objetivos do Estado, que traz na disciplina "uma maneira específica de punir, que é apenas um modelo reduzido do tribunal” (FOUCAULT, 2008, p. 149), que com “a minúcia dos regulamentos, o olhar esmiuçante das inspeções, o controle das mínimas parcelas da vida e do corpo" acaba constituindo um poder disciplinar, que podemos encontrar quando nos voltamos para o espaço escolar (FOUCAULT, 2008, p. 121).

Célia Giglio (2006), ao escrever sobre a inspeção na província paulista, observa que esta era formada pelo inspetor geral, responsável pela “uniformização das práticas", e inspetores de distrito, a "polícia das escolas e dos mestres" (GIGLIO, 2006, p. 354 e 356). Por sua vez, ainda concernente à província paulista, Valdeniza Barra (2006) demarca a similaridade entre o ato de inspecionar e os de vigilância e punição aos docentes, "numa relação na qual o serviço de inspeção era produzido em oposição às práticas não permitidas ao professor" (BARRA, 2006, p. 6189). Na Corte, na província do Rio de Janeiro, a estrutura da inspeção permitia uma ação fiscalizadora ativa e regular e sua intervenção nas escolas “contribuiria para a formação de sujeitos disciplinados, higienizados, religiosos, moralmente idôneos, submissos à lei e ao governo" (BORGES, 2009, p. 14). Ao sul do Brasil, na província de Santa Catarina, era papel da inspetoria geral “educar/controlar os segmentos que participassem do ensino primário e secundário, público ou particular, no intuito de tornar a província um território civilizado, como vinha sendo difundido na Corte" (MARCíLIO, 2006, p. 185). Os estudos comprovam a faceta de vigilância já esperada pela instituição nomeada para inspecionar a instrução pública nas províncias. 
Sem desconsiderar essa forte característica das ações das Inspetorias/Diretorias Gerais da Instrução Pública na segunda metade do Oitocentos, podemos observar que, nas práticas de Inspetores/Diretores Gerais do Ensino, no Paraná, compareciam a fiscalização, assim como a orientação e a defesa de professores, alunos e responsáveis. Os inspetores do ensino não somente fiscalizavam o trabalho dos docentes, mas orientavam, indicavam métodos, livros e procedimentos burocráticos. Outras vezes se posicionavam a favor dos docentes nas questões por esses expostas ou de forma condescendente com os pais e responsáveis que não tinham condições de enviar os filhos para as escolas e que, por isso, não deveriam ser multados de acordo com a legislação em vigor (BARBOSA, 2012). É para esses meandros da inspeção da instrução pública no Paraná que nos voltaremos durante este estudo, com o objetivo não somente de identificar essa administração e sua função, como também localizar que usos e sentidos os responsáveis pela mesma davam para as suas ações frente às escolas, professores, alunos e sociedade no geral.

\section{Inspetoria Geral da Instrução Pública do Paraná: a organização da estrutura e funções}

Podemos apontar o ano de 1854 como aquele em que se deu a reorganização da estrutura da inspeção da instrução pública na província do Paraná. Nossa investigação se volta para o momento de separação oficial do Paraná como comarca da província de São Paulo ${ }^{1}$ (1853) até a década de 1890, quando o novo regulamento de ensino foi organizado, já no período Republicano. Sobre a emancipação paranaense, o período posterior

\footnotetext{
${ }^{1}$ A Lei $n^{\circ} 704$, de 29 de agosto de 1853 - "eleva a comarca de Curitiba na província de São Paulo a categoria de província, com a denominação de Província do Paraná". Curitiba foi eleita capital da recém-criada província considerando: os interesses políticos (de liberais e de conservadores), o aspecto geográfico (a cidade estava na região central da província) e o fator populacional (apontada como a região mais populosa). Antes de Curitiba, outros dois locais foram cotados como possíveis capitais: Guarapuava e Paranaguá. As discussões eram acaloradas para que Paranaguá fosse escolhida, indicando a questão do Porto como um importante diferencial, já que a comunicação com outros locais seria mais rápida do que em Curitiba (WACHOWICZ, 2010). Marcelo Pastre (2009) pontua que a emancipação da província paranaense foi uma concessão do governo imperial para aplacar o descontentamento dos liberais com a excessiva interferência do poder central nas províncias e com os impostos cobrados pelas exportações. Era uma região que despertava o interesse do poder central, pois o comércio de animais - com os tropeiros que vendiam seus rebanhos em Sorocaba - e a exportação da erva-mate ganhava destaque, sem contar o crescimento paulatino da agricultura. Entretanto, o que o autor evidencia é que existia o fator econômico, mas que a Guerra dos Farrapos, no Rio Grande do Sul, foi considerada nesta concessão, pois o governo imperial ponderou o risco de alargamento da onda revolucionária até o Paraná e, deste, até a província de São Paulo (PASTRE, 2009, p. 18).
} 
evidencia o rompimento com os elos administrativos da província de São Paulo, permanecendo os econômicos e os legislativos.

No período inicial da província, a legislação do ensino paulista ainda normatizava as ações dos partícipes da instrução paranaense. Segundo a lei paulista $n^{\circ} 34$, de 16 de março de 1846, a inspeção do ensino, em cada lugar que houvesse aula² pública, seria feita por uma comissão formada por três sujeitos, residentes próximos às escolas, consistindo em "um nomeado pelo governo e dois pela Câmara Municipal, sendo um sacerdote, o qual poderá ser o pároco" (SÃO PAULO. Lei n 34, 16/03/1846). Pelo menos sete comissões de inspeção continuaram constituídas no Paraná, mesmo após a emancipação. Maria Luiza Marcílio (2005) reforça que, com a lei $n^{\circ} 34$, de 16/03/1846, foi definido na província paulista o programa de ensino para as escolas de primeiras letras e que a inspeção estaria ao cargo das Câmaras Municipais, que nomeavam a comissão inspetora. Segundo aponta em seu estudo, não havia remuneração para os sujeitos que inspecionavam as escolas e "a maior parte das comissões nomeadas nunca atuou" na província paulista (MARCíLIO, 2005. p. 68).

Pertinente destacar que, antes da emancipação do Paraná, estava em vigor o Regulamento para a Instrução Pública da província de São Paulo, de 08/11/1851, que reformula a estrutura da inspeção do ensino (SÃO PAULO, Regulamento de Instrução Pública, 1851 , art. $\left.1^{\circ}\right)$. Todavia, aparentemente, ele não entrou em prática na comarca paranaense (no que se refere à estrutura da inspeção: Inspetor Geral, Conselho de Instrução e inspetores de ensino), nem mesmo após sua emancipação, prevalecendo as comissões de inspeção (MUNHOZ, 2012; BARBOSA, 2012). O motivo dessa permanência de atuação das comissões, mesmo após a publicação de uma legislação contrária, não foi possível identificar. A análise interpretativa é a de que permaneceram atuando no território paranaense devido à distância da capital paulista, onde se encontrava o Inspetor Geral que geria os inspetores de distrito. Talvez fosse mais prático deixar na função, independente de como essa agora fosse configurada pela legislação, esses

\footnotetext{
${ }^{2}$ Ressalto que "aula" aqui se constitui como o sinônimo de escola, no sentido de que a aula pública era ministrada por um professor ou professora em local específico para tal, mesmo sendo esta sala de aula um cômodo dentro da residência do docente, como era a grande maioria das aulas públicas na província paranaense. Mesmo quando essa aula de instrução primária era feita em local alugado, pago pelo professor ou subsidiado pelos cofres provinciais, ainda era uma turma em um cômodo e não um prédio com mais de uma turma, era um local de ensino.
} 
senhores que ali já estavam. Muitos desses sujeitos que faziam parte das comissões de inspeção paulista continuaram exercendo a função como inspetor de distrito após a promulgação da lei $n^{\circ} 17$, de 14 de setembro de 1854, que criou os referidos cargos na província do Paraná. Essa permanência de inspetores nos cargos, apesar da mudança de nomenclatura e reorganização da função, mostra que era importante manter pessoas que já tinham certa prática na inspeção da instrução, mesmo que ela fosse reconfigurada.

A iniciativa de romper com o elo legal paulista iniciou-se com duas ações: a primeira foi a reorganização da estrutura da inspeção do ensino paranaense e, a segunda foi a nomeação do primeiro Inspetor Geral de Instrução Pública, que teve, entre suas atribuições, de pensar na contratação e redistribuição de inspetores do ensino e de assumir o compromisso de refletir e propor nova legislação. É possível apontar que a primeira lei a efetivar uma estrutura diferente para a inspeção na província foi a lei $\mathrm{n}^{\circ} 17$, de 14 de setembro de 1854, que instituiu a função do Inspetor Geral da Instrução Pública (IGIP) - nomeado pelo presidente da província, responsável pela instrução primária e secundária - e a existência dos inspetores de distrito em cada lugar onde houvesse uma escola. Entretanto, a função de cada integrante da Inspetoria de Instrução Pública continuou sendo pautada pelo Regulamento de Instrução Pública da Província de São Paulo, de 1851, até que o regulamento paranaense fosse pensado, o que ocorreu em 1857. O rompimento com a legislação paulista de ensino se deu por partes; primeiro se organizou a estrutura e se mantiveram as funções delimitadas pelo regulamento que já continha as especificações dos cargos criados, para depois se pensar em um regimento próprio da província, elaborado de acordo com o seu contexto. O responsável por essa construção foi o Inspetor Geral Joaquim Ignácio Silveira da Mota, que em 1856 formulou os regulamentos paranaenses ${ }^{3}$, sendo aprovados no ano seguinte.

A estrutura da inspeção do ensino e as funções do Inspetor Geral - "chefe de repartição e intermediário" entre o governo e os demais responsáveis pela instrução na província - foram delineadas no Regulamento de Inspeção (1857). Ao todo, foram vinte tópicos destinados a delimitar o papel do Inspetor Geral, que, em síntese, era:

\footnotetext{
3 Regulamento de Ordem Geral para as escolas da Instrução Primária (08/04/1857); Regulamento de Inspeção da Instrução Pública da Província do Paraná (24/04/1857) e o Regulamento para a Secretaria da Inspetoria Geral da Instrução Pública do Paraná (30/10/1857).
} 
inspecionar, instruir, dirigir todos os empregados da instrução; prestar contas e informação ao presidente e emitir relatório até o último dia do ano; manter a disciplina e observância às leis nas escolas; criar e presidir os concursos e exames dos professores; julgar a suspensão e repreender professores quando necessário, incluindo os particulares; visitar as escolas da província (por si ou por pessoa de reconhecida ilustração a quem delegar); convocar os Conselhos Literários sobre qualquer objeto concernente ao ensino; orientar a escrituração dos livros da escola (matrícula, mobília e utensílios); organizar a tabela de mobília e utensílios que cada escola deveria ter; propor a nomeação do seu secretário, dos inspetores de distrito e subinspetores e alteração dos distritos; autorizar a experiência de novos métodos de ensino e expedir regulamentos sobre o programa de estudos nas escolas, exames e habilitação de professores (PARANÁ, Regulamento de Inspeção, 1857, art. $3^{\circ}$ ). O modo como a Inspetoria Geral da Instrução Pública da província do Paraná se estruturou nos primeiros anos de sua existência está disposto abaixo:

Organograma 1: Estrutura da Inspeção do Ensino no Paraná Comarca e Província (1846-1857)

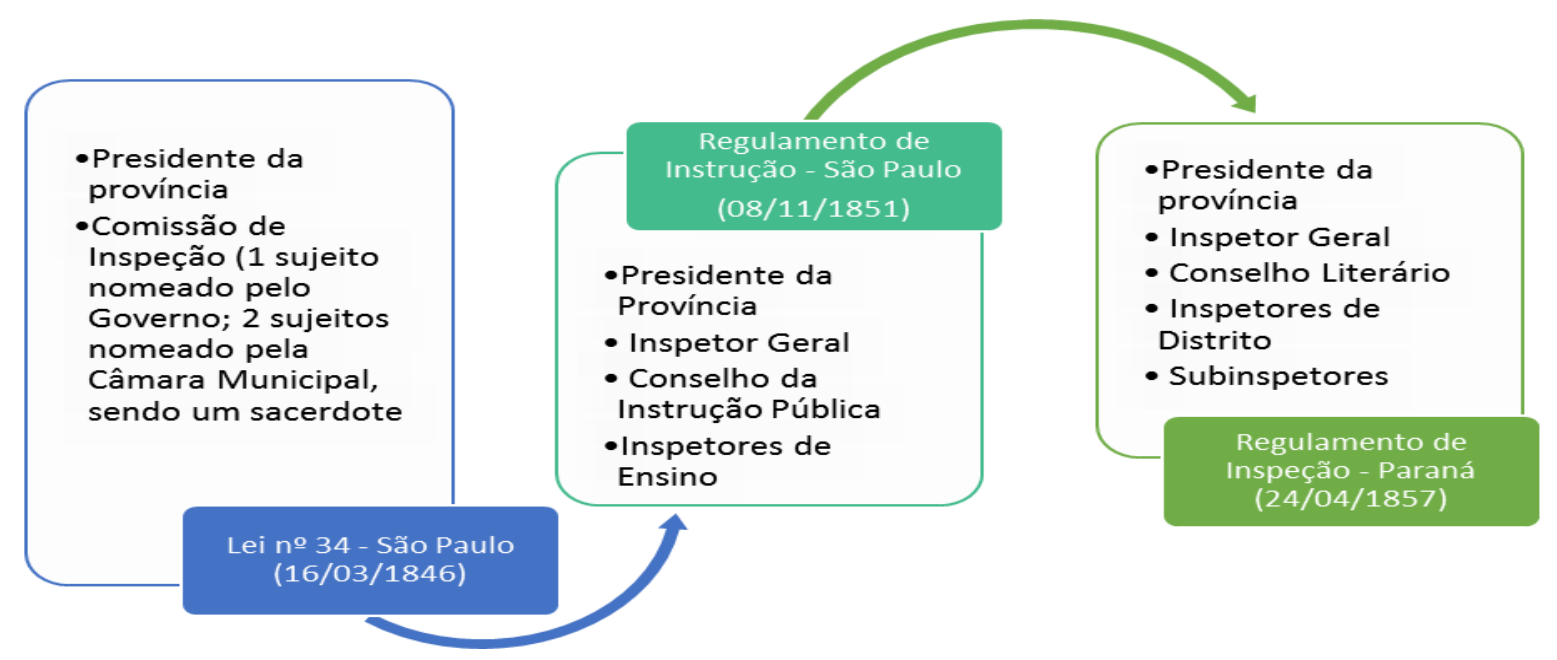

Fonte: Legislação da província de São Paulo e da província do Paraná.

No Regulamento de Inspeção foi descrita a função dos Conselhos Literários: visitar as escolas e os estabelecimentos onde houvesse aula dentro do distrito de instrução, fazer o exame do estado da instrução primária e secundária no referido, bem como do plano geral e particular de estudos de cada escola, observando os livros, o regime, a economia, a habilitação dos professores e dando relato de tudo ao Conselho, ao Inspetor 
de Distrito e ao Inspetor Geral da Instrução Pública. Os Conselhos Literários seriam formados pelos vigários, presidentes das Câmaras ou delegados das mesmas, subinspetores e inspetor de distrito, com uma sessão anual.

Porém, nos documentos trocados entre as autoridades do ensino (professores, subinspetores, inspetores de distrito/paroquiais, inspetor geral e representantes da câmara, quando nomeados a responder como tal), nos anos posteriores ao Regulamento de Inspeção (1857), não foram encontradas muitas referências à atuação do Conselho Literário. As funções como visitar as escolas, lançar o termo de visita no livro competente, discorrer sobre o estado da instrução no respectivo distrito e sobre os assuntos referentes ao ensino ainda continuavam exercidas, pelo menos em sua maioria, pelos inspetores e subinspetores, auxiliados pelas câmaras municipais quando necessário. (BARBOSA, 2012, p. 216)

Apesar da ausência de documentos que comprovem a sua atuação, conselheiros foram nomeados pela Inspetoria para o Conselho Literário do distrito de Curitiba, Castro e Paranaguá (BARBOSA, 2012, p. 217). Nas décadas seguintes, a estrutura da inspeção sofreu novas mudanças:

Organograma 2: Estrutura da Inspeção do Ensino no Paraná Província e Estado (1874-1890)

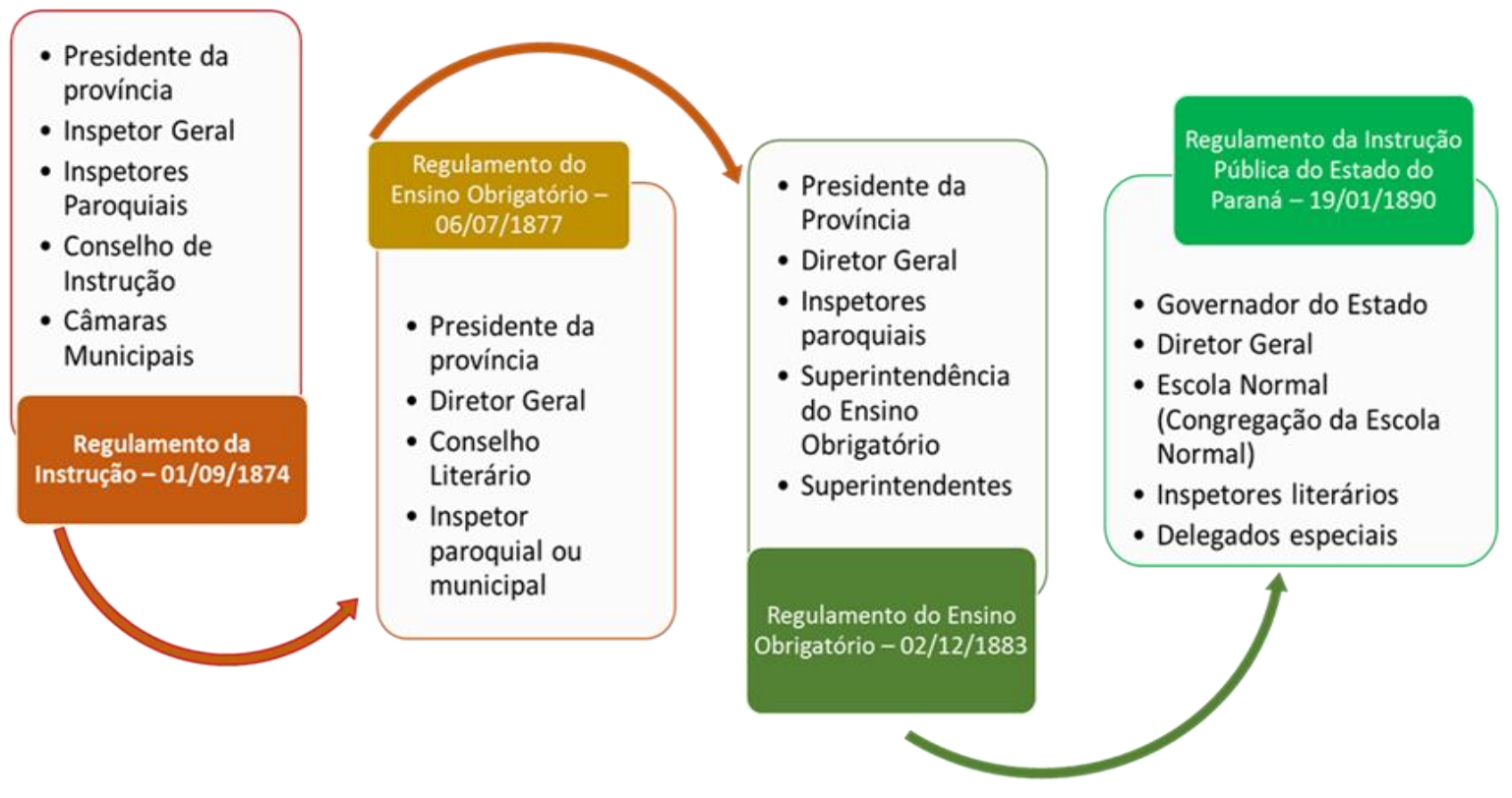

Fonte: Legislação do Paraná. 
Nota-se que o Regulamento de 1874 prevê a existência do Conselho de Instrução, formado pelo presidente da Câmara, pelo inspetor paroquial, o pároco e o coletor das rendas provinciais. Esse conselho tem função semelhante ao anterior, contudo, agrega-se o arrolamento escolar de todos os menores em idade de frequentar a aula, a publicação na imprensa ou a fixação em lugares públicos dessa listagem e a imposição de multas aos pais e tutores que não enviassem as crianças às escolas. Ao contrário dos primeiros Conselhos Literários, os de Instrução deixaram documentos de sua atuação nas correspondências de governo ${ }^{4}$, de acordo com o previsto na legislação.

Em 1876, o conselho recebe nova nomenclatura e desdobramento de função. Chamado de Conselho Literário, deixa de ter a função de arrolamento da população em idade escolar e de ser um conselho em cada distrito para ser uma instituição localizada na capital, que enviava pareceres com as medidas que julgava pertinentes para o ensino na província, julgava as faltas cometidas por professores, indicava compêndios para as aulas primárias e secundárias, bem como métodos de ensino ${ }^{5}$. Era formado pelos professores do Instituto Paranaense e Escola Normal e dirigido pelo Diretor Geral da Instrução Pública. Por sua atuação articulada e entrecruzada com a inspeção e instrução pública, "os Conselhos na província podem ser comparados como braços da inspeção" (BARBOSA, 2012, p. 242).

Como esboçado de forma resumida, durante o período aqui investigado ocorreram alterações quanto à nomenclatura de algumas funções da Inspetoria, porém, as orientações para a inspeção continuaram praticamente sem muita transformação, até a criação da Superintendência do Ensino Obrigatório, em $1883^{6}$. Segundo o disposto em regulamento, cada localidade (cidade, vila ou povoação) era uma circunscrição escolar, dividida em distritos e cada uma dessas teria um superintendente. Quando o número fosse maior do que quatro superintendentes, haveria um chefe para a Superintendência do Ensino Obrigatório. Todos os envolvidos, chamados de "auxiliares do ensino obrigatório", eram nomeados pelo presidente da província e não recebiam remuneração

\footnotetext{
${ }^{4}$ Ver BARBOSA, p. 214.

${ }^{5}$ Cabia, ainda, ao Conselho Literário, a organização da folha de pagamento dos professores do Instituto Paranaense e Escola Normal, registrando as reuniões em livro ata.

${ }^{6}$ A Superintendência do Ensino Obrigatório, transformada posteriormente em Superintendência do Ensino e com algumas reformulações, se manteve atuando por 33 anos, sendo extinta pela lei $n^{\circ} 1.555$, de 04 de março de 1916.
} 
para tal atividade. Cabia aos superintendentes do ensino obrigatório a promoção, fiscalização e informação sobre a frequência escolar ${ }^{7}$. Os deveres e as atribuições dos chefes da Superintendência do Ensino Obrigatório tinham algumas semelhanças com os dos superintendentes:

Organizar a propaganda e efetividade da obrigação escolar na circunscrição de sua alçada; fiscalizar e ajudar o serviço dos superintendentes dos distritos; visitar as escolas e informar sobre o estado e necessidade delas; reunir os superintendentes em junta, quando o julgar conveniente para deliberarem sobre o serviço do ensino obrigatório; enviar ao presidente da província, por intermédio do Diretor Geral da Instrução Pública, um relatório trimensal sobre o serviço do ensino obrigatório em sua circunscrição; propor ao presidente da província o nome de um cidadão idôneo para o cargo de roupeiro dos alunos indigentes; ordenar por escrito, anuindo ao pedido dos superintendentes, que $o$ roupeiro forneça roupas às crianças nominalmente designadas; superintender 0 serviço desses fornecimentos dando conta dele em seu relatório trimensal; solicitar das repartições fiscais, câmaras municipais ou associações particulares, organizada para esse fim, a quantia ou os vestuários necessários para o fornecimento das crianças indigentes; propor, quando julgar conveniente ao presidente da província, a nomeação de algumas senhoras para comporem uma comissão auxiliar da obrigatoriedade do ensino; solicitar às autoridades civis, policiais ou eclesiásticas os auxílios e informações convenientes ao desempenho dos direitos e deveres escolares; assistir aos exames gerais dos direitos e deveres escolares. (PARANÁ, REGULAMENTO DO ENSINO OBRIGATÓRIO. 1883, art. 13º)

Observa-se na atribuição dada aos chefes das Superintendências do Ensino Obrigatório e aos superintendentes, que ocorreu um deslocamento das obrigações que eram, anteriormente, dos inspetores paroquiais e dos professores. Até então, cabia aos inspetores paroquiais verificar a matrícula e a frequência nas aulas públicas e particulares e, havendo disparidade, deveria se reportar ao Diretor Geral da Instrução. Era o inspetor paroquial que julgava se os motivos das faltas dos alunos, mesmo previstos na

\footnotetext{
7 Promover a frequência às escolas, fazendo propaganda assídua entre as famílias de seus respectivos distritos, do dever escolar, envidando todos os recursos de persuasão, estimulando as indiferenças; dissuadindo os preconceitos; convencendo as recalcitrâncias e reagindo com os meios coercitivos que este regulamento prescreve contra as obstinações rebeldes; visitar frequentes vezes as escolas e informar o inspetor paroquial das irregularidades que nelas verificarem; pedir vestuário para as crianças, privadamente indigentes de seu distrito, ao chefe da superintendência; oferecer um relatório trimensal ao chefe da superintendência, sobre o serviço a seu cargo (PARANÁ, REGULAMENTO DO ENSINO OBRIGATÓRIO. 1883, art. $\left.12^{\circ}\right)$.
} 
legislação ${ }^{8}$, eram legítimos (art. $32^{\circ}$ ). Previsto em regulamento, inspetor paroquial e professores trabalhavam em "comum acordo" na observância da matrícula e frequência $\left(\right.$ art. $\left.35^{\circ}\right)$, cabendo ao último transmitir todos os meses as listas das faltas (art. $13^{\circ}$ ) e declarar mensalmente o nome dos alunos presentes e o dos seus pais e tutores (art. $14^{\circ}$ ). Quanto à vestimenta dos alunos, contava a inspeção com a participação das Câmaras Municipais, que a fornecia para os meninos considerados indigentes e que, por não terem vestuário, não frequentavam a escola (art. 15²) (PARANÁ. Regulamento do Ensino Obrigatório, 1877). A criação da Superintendência do Ensino Obrigatório elimina essas funções e configura um grupo seleto de senhores para lidar com a matrícula e frequência, ficando ao encargo dos inspetores paroquiais a observação da parte administrativa (livros dos termos de visita, livros de matrícula, arrolamento do mobiliário e dos materiais escolares, licenças de professores) e pedagógica (método utilizado, exames de alunos).

Em relatório, o presidente Luiz Alves Oliveira Bello (1884) descreve as suas impressões da instrução pública quando assumiu o cargo, pontuando que seu estado não condizia com o que era esperado, sendo necessária uma reforma, principalmente que pensasse em uma “inspeção assídua e dedicada” (BELLO, 1884, p. 34). Em suas palavras: "procurei, visitando com assiduidade as aulas, fazendo-as frequentar pelos superintendentes do ensino obrigatório, corrigir vícios de métodos antiquados e estimular o zelo dos preceptores" (Ibidem, idem). Nesse sentido, ele reforça que tinha a preocupação com a estrutura da inspeção, das escolas suficientes para o número de alunos, em relação com a instituição do ensino obrigatório e foi isso que levou em consideração ao propor à Assembleia Legislativa Provincial a reforma na legislação, que acarretou na publicação do Regulamento do Ensino Obrigatório, de 03/12/1883. Quanto ao debate sobre o ensino obrigatório, existente entre os responsáveis pela inspeção e instrução pública em diferentes províncias e países, o presidente reage de forma prática, demonstrando que tem ciência e que segue com a reforma sem pensar nas objeções teóricas.

\footnotetext{
${ }^{8}$ São consideradas causas legítimas para a interrupção da frequência nas escolas, a juízo do inspetor paroquial: doenças das crianças, falecimento de algum membro da família, viagens urgentes, mau tempo, distância de 2 km da sede da escola (PARANÁ, REGULAMENTO DO ENSINO OBRIGATÓRIO. 1877, art. $32^{\circ}$ ).
} 
Há muito que essa medida, da frequência imperativa, estava na legislação do país, como um desideratum, mas também como um compromisso. 0 regulamento de 17 de fevereiro de 1854, na Corte a consagra; os conselheiros Eusébio de Queiroz, em 1863, Paulino de Souza em 1870, João Alfredo em 1874, e a comissão parlamentar da instrução pública em 1880 insistiram sobre a urgência de adotá-la, e ofereceram ideias e projetos, quase todas as províncias, inclusive esta, tem em suas coleções legislativas decretos, regulamentos; no entanto, o ensino obrigatório continuava uma aspiração platônica e uma reforma de interesse palpitante. (BELLO, 1884, p. 39)

Sua escrita deixa entrever que estava ciente das proposições legais feitas na Corte e que, não somente na capital do Império como também em outras províncias, havia um esforço legislativo para com as questões do ensino. O presidente diz que se fizeram algumas perguntas quando pensou na reforma do ensino na província paranaense: "a inspeção do ensino em todo país é como tem sido feita até aqui, nas localidades? Não são gratuitas essas funções? Não há inspetores que têm assinalado por seu zelo vivaz e desinteressado? Não os há mesmo na província?" E ainda, "por que não havia de acertar com um grupo de cidadãos, tomados entre os mais grados de todas as opiniões políticas, capazes de se incumbirem ativa e tenazmente das obrigações que lhes prescrevesse 0 regulamento da frequência imperativa?" (BELLO, 1884, p. 39). Por fim, retoma artigos do Regulamento de 1883 e enfatiza: "a base de todo o serviço é a comissão de superintendência, tudo depende dela, e pela medida de seu zelo se poderá aferir a situação próspera ou paralisada da frequência imperativa na localidade de sua alçada" (BELLO, 1884, p. 40). Para além do debate sobre a constituição do ensino obrigatório na província paranaense e como ele comparece em outros locais, interessa nesse momento o reforço que o presidente Oliveira Bello faz do papel da inspeção do ensino para a efetiva constituição da obrigatoriedade e a indicação de que ela deveria ser formada por cidadãos zelosos e que tivessem diferentes opiniões políticas e de constituição partidária diversa, ou seja, inspetores que mesmo opinando e pensando de forma desigual tivessem o zelo e a preocupação com o desenvolvimento da instrução como cerne de sua prática. Ele dividiu a província em 17 circunscrições do ensino obrigatório, denominadas: $1^{\text {a }}$

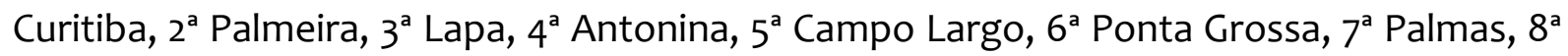
Morretes, $9^{\mathrm{a}}$ Rio Negro, $10^{\mathrm{a}}$ São José dos Pinhais, $11^{\mathrm{a}}$ Guarapuava, $12^{\mathrm{a}}$ Castro, $13^{\mathrm{a}}$ Anhaia, $14^{\mathrm{a}}$ Assungui, $15^{\mathrm{a}}$ Porto de Cima, $16^{\mathrm{a}}$ Tibagi, $17^{\mathrm{a}}$ Arraial Queimado. 
Cada circunscrição listada era regida pelo Chefe da Superintendência do Ensino Obrigatório que a subdividia em distritos, onde atuavam os superintendentes do ensino obrigatório. Dessa forma, tecia-se uma rede de inspeção da instrução pública, abarcando não somente a verificação e orientação quanto aos métodos, compêndios, utensílios escolares, mapas, relatórios, etc. - que ainda estavam ao cargo dos inspetores paroquiais - como também o acompanhamento intensivo da matrícula, frequência e arrolamento das crianças entre 7 e 14 anos que não estivessem ainda na escola - papel dos superintendentes do ensino obrigatório. Finalizando, Oliveira Bello pondera: “o esforço das comissões, a solicitude dos superintendentes; não era uma roda mais do mecanismo burocrático o que me propunha criar, era uma instituição popular (...)" (BELLO, 1884, p. 40). E pensando dessa forma, nomeou aqueles que estariam à frente das Superintendências do Ensino Obrigatório em todas as cidades e vilas da província paranaense:

Quadro 1: Os responsáveis pelas Superintendências do Ensino Obrigatório

\begin{tabular}{|c|c|}
\hline $\begin{array}{c}\text { Local da Superintendência do Ensino } \\
\text { Obrigatório }\end{array}$ & $\begin{array}{c}\text { Chefe da Superintendência do Ensino } \\
\text { Obrigatório }\end{array}$ \\
\hline Curitiba & João Pereira Lagos \\
\hline Palmeira & Moysés Marcondes de Oliveira e Sá \\
\hline Lapa & Conrado Caetano Erichsen \\
\hline Antonina & João Manoel Ribeiro Vianna \\
\hline Campo Largo & Augusto Lobo de Moura \\
\hline Ponta Grossa & Vicente Machado da Silva Lima \\
\hline Palmas & Estevão Ribeiro do Nascimento \\
\hline Morretes & José Jacintho Linhares \\
\hline Rio Negro & João Bley \\
\hline São José dos Pinhais & Joaquim Ignácio Silveira da Motta Júnior \\
\hline Guarapuava & Josto Dias Larangeiras \\
\hline Castro & Antonio de Souza Dias Negrão \\
\hline Anhaia & Padre Celso Cesar da Cunha \\
\hline Assungui & José Ribeiro de Macedo \\
\hline Porto de Cima & Gabriel Ribas Cordeiro Netto \\
\hline Arraial Queimado & \\
\hline
\end{tabular}

Fonte: Quadro elaborado pela autora a partir dos Relatórios de presidentes da Província (1884 a 1886). 
Não consta nos relatórios subsequentes ao de Oliveira Bello (1884) quem era o Chefe da Superintendência do Ensino Obrigatório da $16^{\text {a }}$ circunscrição (Tibagi) ${ }^{9}$. Durante esse período, as escolas de Tibagi eram visitadas pelo inspetor paroquial Zeferino Alves de Castro Machado. Talvez, na falta de um trabalho próprio do superintendente do ensino obrigatório, a Diretoria Geral da Instrução Pública lançasse mão do inspetor paroquial, contudo, não há o registro dessa transferência de função.

Ainda sobre o quadro anterior, com exceção de José Ribeiro de Macedo, Antonio de Souza Dias Negrão, Vicente Machado da Silva Lima e Gabriel Ribas Ribeiro Neto, todos os outros chefes das superintendências haviam exercido a função de inspetor anteriormente na província, ou seja, estavam a par de como funcionava a instrução e o papel daquele que a inspeciona. Quatro deles - João Pereira Lagos, Moysés Marcondes de Oliveira e Sá, Augusto Lobo de Moura e Ernesto Dias Laranjeiras - haviam sido Diretores Gerais da Instrução, o que Ihes daria um conhecimento amplo de todo o funcionamento da estrutura da inspeção na província. Eram sujeitos que foram constantes não somente na função de inspetores como também nos debates de questões sobre a instrução que ocorriam na Assembleia Legislativa, nas Sociedades e Clubes Literários e nas folhas periódicas que circulavam no Paraná. O que possibilita observar é que a estrutura e o papel da inspeção paranaense se modificam, porém os sujeitos que a compõem se mantêm, na maioria dos casos.

Durante o ano de 1884 é possível encontrar as convocações que João Pereira Lagos fez para os superintendentes dos 16 distritos em que estava subdividida a circunscrição da capital: "o Chefe da Superintendência do Ensino Obrigatório convida os senhores superintendentes para uma reunião que realizar-se-á amanhã, a 1 hora da tarde, no Palácio da Presidência, afim de tratar de assunto de interesse do mesmo ensino" (CHEFE..., 1884, p. 03). Essa primeira convocação, assim como outras notícias das Superintendências do Ensino Obrigatório, ocorreu no mês seguinte à publicação do Regulamento do Ensino Obrigatório (1883) no jornal (CONVOCAÇÃO..., 1883, p. 01). Acompanhando esses desdobramentos no jornal após a divulgação da legislação, fica visível que a reestruturação da inspeção foi rápida. E isso não pode ser visto como um

\footnotetext{
${ }^{9}$ Até o momento, também, não encontramos essa informação nas correspondências de governo. Em 1888, Júlio de $M$. Taques aparece na documentação como o Chefe da Superintendência do Ensino Obrigatório de Tibagi (AP0848, 25/01/1888, p. 249).
} 
trabalho menor, se considerarmos que, além dos chefes eram nomeados os superintendentes, o que demandava tempo e noção de quem, em cada localidade, teria o mínimo de conhecimento sobre o ensino para exercer tal atividade.

Em 1885, a Assembleia Legislativa Provincial, com a assinatura do deputado Generoso Marques dos Santos, que já havia exercido a função de Inspetor Geral da Instrução, decreta que "o diretor geral da instrução pública é o chefe do ensino obrigatório em toda a província (art. $\left.1^{\circ}\right)$ ", competindo a ele a inspeção do serviço realizado pelas Superintendências, o recebimento de todos os relatórios trimensais realizados pelos Chefes das Superintendências do Ensino Obrigatório, bem como a compilação dos mesmos para o envio ao final do ano do relatório final ao presidente da província, constando mapa demonstrativo da frequência escolar comparando-o com os dados do ano anterior (art. $2^{\circ}$ ). O decreto suprime o cargo de inspetor paroquial nos locais onde já fosse estabelecido o ensino obrigatório, sendo que "as atribuições que pertenciam a estes funcionários serão exercidas pelos chefes da superintendência do ensino obrigatório" (art. $3^{\circ}$ ) (DECRETO..., 1885, p. 02). Tal normatização demonstra que houve um reforço legal do papel central que se mantinha do Diretor Geral da Instrução Pública, independentemente das funções desenvolvidas pelos chefes das superintendências que, além de serem responsáveis pelo trabalho dos superintendentes, eram pessoas que já haviam exercido papel fundamental na inspeção da instrução, o que poderia causar alguns estranhamentos dentro da hierarquia da Diretoria Geral da Instrução Pública.

Outro ponto interessante é a supressão dos inspetores paroquiais. A princípio, a obrigatoriedade abarca praticamente todas as cidades e vilas da província, no entanto, não existiam somente as escolas públicas primárias, havia as escolas subvencionadas e as particulares, que continuavam recebendo a visita do inspetor paroquial, pois não seguiam a exigência da matrícula e frequência imperativa. Essa disposição continua nos anos posteriores e, em 1889, o presidente da província, Jesuíno Marcondes de Oliveira e Sá, com a aprovação da Assembleia Legislativa, cria cem escolas primárias subvencionadas, cabendo aos inspetores paroquiais exigir dos professores a remessa trimestral "e competentemente rubricados dos mapas de frequência, filiação, idade, moralidade e 
aproveitamento dos alunos, para serem transmitidos à diretoria da instituição pública" (PARANÁ. Regulamento, 31/10/1889, art. $5^{\circ}$ ).

Tempos depois, a inspeção da instrução pública novamente sofre mudanças quanto à estrutura e às funções, por meio do Regulamento da Instrução Pública de 1890. As Câmaras Municipais ganham uma responsabilidade oficial, sendo independentes da direção central do ensino as escolas por elas criadas com recurso próprio (art. $30^{\circ}$ ) e devendo fornecer aos alunos pobres penas, tintas, papel e os compêndios necessários (art. $\left.16^{\circ}\right)$. Não existem as Superintendências do Ensino Obrigatório, contudo, as atribuições a elas conferidas poderiam ser deslocadas às "comissões para promover a frequência escolar", presididas pelos inspetores literários (art. 33\%). Os referidos inspetores deveriam visitar as escolas uma vez por semana (art. 54 $4^{\circ}$, sendo seus substitutos natos os juízes de paz (art. 50²). À Congregação da Escola Normal coube a função de organizar o regimento da Escola Normal, bem como tratar das questões a ela relativas e, ainda, assumiu a função que antes era do Conselho Literário de 1876, tendo como competência a emissão de "parecer sobre todos os assuntos relativos à instrução, que não forem de mero expediente (art. 52 $2^{\circ}$ ". Além desses, ainda existiam os delegados especiais, nomeados eventualmente pelo governo do Estado para exercer a inspeção, que poderiam ter o auxílio do Pedagogo da Escola Normal para "visitar e fiscalizar as escolas, assim como indicar aos professores os métodos e programas convenientes" (PARANÁ. Regulamento da Instrução Pública do Paraná, 1890, art. 54º).

No mesmo ano, o governador Américo Lobo Leite Pereira assina o decreto $n^{\circ} 84$, de 21/05/1890, que cria a função do Superintendente Geral do Ensino Público, responsável por toda a inspeção no Paraná e com a incumbência de, no prazo de dois meses, apresentar ao governo "um regulamento completo para o ensino primário e secundário" (PARANÁ. Decreto $n^{\circ} 84,21 / 05 / 1890$, art. $2^{\circ}$ ). Aquele que exercia a função de Diretor Geral da Instrução Pública passa a Diretor do Instituto Paranaense e da Escola Normal (Ibidem, art. $4^{\circ}$ ). Podemos indicar que o momento de instituição desse decreto rompeu com uma estrutura que se manteve durante toda a segunda metade do Oitocentos no Paraná. Não somente pela criação de um cargo, mas pela função centralizadora que dessa reorganização decorreu. Até então, o Diretor Geral da Instrução contava com uma estrutura que o auxiliava nas decisões sobre o ensino e, nas décadas de 1880 e 1890, a 
essa estrutura ainda eram agregadas comissões nomeadas para pensar as reformas, como a que organizou o Regulamento da Instrução Pública do Paraná, de 1890. Antes do decreto $n^{\circ} 84$, José Joaquim Franco Valle era o Diretor Geral da Instrução Pública. Como previsto, ele passou a ser o diretor do Instituto Paranaense e da Escola Normal, sendo nomeado Vicente Machado como Superintendente Geral do Ensino Público.

\section{Voltando rapidamente o olhar para o paranaense Vicente Machado da Silva Lima} (1860-1907), Segundo descreve Maria Nicolas (1954), ele era bacharel em Direito pela Faculdade de São Paulo (cursando no período de 1876 a 1881) e, assim que se formou, foi nomeado promotor público de Curitiba (1881). Exerceu cargos diversos no Paraná, tais como: juiz municipal e de órfãos, em Ponta Grossa, chefe de polícia, presidente da Câmara, deputado federal e "presidente e membro de diversas comissões de alto valor político" (NICOLAS, 1954, p. 162). As páginas dos jornais paranaenses confirmam sua presença em vários cargos na província e, por meio delas, verifica-se que ocorreu uma reunião dos seus amigos, na tipografia do jornal $A$ República, no qual era redator ${ }^{10}$, para comemorar a sua nomeação "para o importante cargo de Superintendente do Ensino Público" (A REUNIÃO, 1890, p. 03). Dois dias depois, os detalhes da reunião foram publicados. Da tipografia do jornal, o grupo foi precedido pela banda de música do $17^{\circ}$ batalhão de infantaria até a casa de Vicente Machado, onde ocorreram vários brindes e discursos sobre a nomeação, com a festa se estendendo até as vinte e duas horas, para os amigos mais íntimos (A REUNIÃO, 1890, p. 03). Contudo, a atuação de Vicente Machado no ensino paranaense não se iniciou com essa nomeação. Um ano após sua formação como bacharel em Direito, Vicente Machado foi professor interino de Filosofia e Noções de Direito Público, no Instituto Paranaense (VICENTE..., 1882, p. 03). Dois anos depois, uma nota no jornal nos informa que foi criada a $6^{\text {a }}$ circunscrição do ensino obrigatório na província:

A importante cidade de Ponta Grossa, seguindo o exemplo de suas coirmãs, pediu a decretação da obrigatoriedade do ensino. Acedendo a tão louvável pedido, o Exmo. Sr. Dr. Presidente da Província nomeou chefe da superintendência naquela cidade o Dr. Vicente Machado da Silva Lima.

\footnotetext{
${ }^{10}$ No dia seguinte, saiu uma nota no jornal Sete de Março, cujo redator era Justiniano de Mello e Silva (um dos que organizaram o Regulamento da Instrução Pública, de 1890): "Vicente Machado, redator de República desta cidade, passa a ser Superintendente do Ensino Público por decreto criado" ( NOMEAÇÃO... 1890, p. 04).
} 
Já não é uma grandiosa esperança a obrigatoriedade do ensino na província; é uma esplêndida realidade que perpetuará o nome, já por muitos títulos distinto, do Exmo. Sr. Dr. Luiz Alves Leite de Oliveira Bello. (CIRCUNSCRIÇÃO..., 1884, p. 03)

O jornal enfatiza que o pedido pela obrigatoriedade do ensino partiu da cidade de Ponta Grossa e não da presidência da província ou da Diretoria Geral da Instrução Pública. A nota também informa que a obrigatoriedade do ensino não estava apenas no planejamento, mas já se configurava como uma realidade, elogiando ainda Oliveira Bello, que organizou o Regulamento do Ensino Obrigatório (1883). E Vicente Machado comparece como aquele que iniciaria a ação da Superintendência do Ensino Obrigatório em Ponta Grossa. Sua indicação para a função pode ter sido feita não somente pelas ações que já desempenhara na província, como também por ser ele presidente da Sociedade Protetora do Ensino Obrigatório em Ponta Grossa (VICENTE..., 1884, p. 01). Tudo indica que tal sociedade, assim como a homônima que existia em Vila de Palmas, tenha sido uma das instituições que se manifestaram em favor da criação da circunscrição do ensino obrigatório em Ponta Grossa. Em fevereiro de 1884, o presidente da província comunica às Sociedades Protetoras do Ensino em Ponta Grossa e Vila de Palmas que, de acordo com os artigos 51 e 53 do regulamento, resolve declarar ali estabelecida a obrigatoriedade. Segundo o disposto em tais artigos:

Art. $51^{\circ}$ O presidente da província ordenará que se cumpram as disposições deste regulamento, declarando instituído de fato o ensino obrigatório, nas cidades, vilas ou povoados, que estejam em condições adequadas, e onde, ou pela câmara municipal ou por alguma associação ou outros meios, se ofereçam elementos para a formação e mantença do fundo escolar. Art. $53^{\circ}$ Cada circunscrição receberá para distinguir-se um número de sua inscrição, na lista das localidades em que o ensino obrigatório estiver efetivamente consagrado. (PARANÁ. REGULAMENTO DO ENSINO OBRIGATÓRIO, 03/12/1883, art. 51 e 53)

Conforme o regulamento, as sociedades, em conjunto com as Câmaras Municipais, ofereceriam a base para a efetivação da obrigatoriedade do ensino. No relatório que Vicente Machado envia ao presidente Oliveira Bello, ele descreve como organizou a reunião da Sociedade Protetora do Ensino Obrigatório em Ponta Grossa, que contava com 
mais de cinquenta sócios, cada um pagando uma mensalidade de 1\$000, "convindo notar que muitos cidadãos generosos auxiliavam com quantia muito superior mensalmente"

(...) Reuniram-se a convite meu, no salão da Câmara Municipal, diversos cidadãos, que, estimulados pela generosa propaganda com que V. Exa. procurava tornar obrigatório o ensino primário na província, e para que com eficácia pudesse ser posto em prática o Regulamento de 3 de dezembro, resolveram criar uma associação que ficou denominada Protetora do ensino obrigatório, com o fim de auxiliar a infância indigente. (...). Das crianças arroladas, apenas 8 reclamam vestuário, de modo que com a receita avantajada poderá a referida associação criar prêmios, concorrer para o melhoramento do material escolar e outros benefícios em prol do ensino público. Como presidente da associação Protetora do Ensino tudo farei por bem utilizar o que a generosidade do povo dispensa a favor das crianças. (RELATÓRIO..., 1884, p. 01)

Como Vicente Machado informa, a Sociedade Protetora do Ensino Obrigatório dispunha de condições financeiras para garantir um fundo escolar para auxiliar a efetivação da obrigatoriedade na cidade de Ponta Grossa, fornecendo a base material para a permanência das crianças nas escolas. Naquele mesmo ano, Vicente Machado e outros oito superintendentes ${ }^{11}$ receberam o grau da Imperial Ordem da Rosa" "pelos relevantes serviços prestados ao ensino obrigatório" (PARANAENSES..., 1884, p. 02). Com exceção de Vicente Machado, Manoel Pedro dos Santos Lima e João Manoel Ribeiro Vianna, todos os que receberam a Imperial Ordem da Rosa já haviam exercido a função de inspetor da instrução na província. Destes, quatro foram Inspetores/Diretores Gerais da Instrução Pública: Generoso Marques dos Santos, João Pereira Lagos, Moysés Marcondes de Oliveira e Sá e Augusto Lobo de Moura. O recebimento do título honorífico indica o destaque dado a Vicente Machado e outros superintendentes do ensino obrigatório, como também permite identificar que, a maioria daqueles que o receberam, já possuíam experiência na função de inspetor do ensino. Tal permanência possibilita apontar que as mudanças de cargos e papéis desempenhados na Inspetoria/Diretoria

\footnotetext{
${ }^{11}$ Generoso Marques dos Santos, João Pereira Lagos, Moysés Marcondes de Oliveira e Sá, Manoel Pedro dos Santos Lima, Augusto Lobo de Moura, Conrado Caetano Erichsen, João Manoel Ribeira Vianna, José Jacintho Linhares.

${ }^{12}$ A Imperial Ordem da Rosa era um ordenamento brasileiro de honra, que premiava militares e civis, sendo brasileiros ou estrangeiros, que se distinguissem por sua fidelidade ao Imperador e pelos serviços prestados ao Estado (SILVA, 2011).
} 
Geral da Instrução Pública não ocasionavam necessariamente a renovação do quadro de inspetores. Aqueles que exerceram a direção da inspeção na província ou que na sua função como inspetor paroquial/distrital se destacaram, foram nomeados como chefes das Superintendências do Ensino Obrigatório em sua localidade. Contratavam-se novos inspetores e superintendentes do ensino, mas se mantinha nas funções centrais da inspeção aqueles que, de preferência, já possuíam uma experiência maior.

Durante o período que Vicente Machado esteve como Superintendente Geral do Ensino no Paraná, todas as correspondências, ofícios e questões de governo foram a ele encaminhados. Nesse sentido, muitos inspetores literários enviavam seus relatórios e mapas das escolas por eles visitadas, professores solicitavam licença ${ }^{13}$ e livros de matrícula ${ }^{14}$, entre outros. Mesmo com toda a centralidade de decisão, bastaram nove meses de instituição do cargo de Superintendente Geral do Ensino para que se voltasse à estrutura antiga. Em 1891, nas páginas de outro periódico, lê-se a notícia: "pelo governo foi suprimido esse cargo, verdadeiro sorvedouro dos dinheiros públicos, depois de ter demitido o respectivo superintendente, Dr. Vicente Machado. Muito bem!” (O NOTÍCIAS..., 1891, p. 03). Dois meses depois, com a publicação do Regulamento do Ensino Obrigatório, a organização da inspeção mantém a sequência de cargos já conhecida: governador do Estado, Diretor Geral da Instrução, inspetores literários e comissões de ensino (PARANÁ. REGULAMENTO DO ENSINO OBRIGATÓRIO, 14/05/1891).

\section{Conclusão}

Aponto, com base em estudos sobre a inspeção da instrução pública no Oitocentos, que a mesma, como instituição responsável pela educação escolarizada, teve papel central no compartilhamento dos ideais de progresso e civilidade e que os inspetores comparecem como promotores e protagonistas nas propostas para o ensino e para trânsito de ideias educativas, entendendo-os inseridos em uma estrutura maior, na

\footnotetext{
${ }^{13}$ Como o fez a professora Alzira Braga dos Santos, de Ponta Grossa, cidade onde Vicente Machado desenvolveu a Superintendência do Ensino Obrigatório, em 1884 (APogoo, 26/10/1890, p. 09).

${ }^{14}$ Como o fez a professora Fernandina Mendes de Castro Amaral, de Pirahy (AP0898, 10/09/1890, p. 170).
} 
qual o percurso de ideias estava permeado pelas relações sociais em diferentes lugares institucionais ${ }^{15}$.

Acompanhar a formação da estrutura da Inspetoria Geral da Instrução Pública na província do Paraná, por meio daqueles que exerceram a função de Inspetor Geral/Diretor Geral ou inspetores de distrito/paroquiais, é identificar a existência de uma representação ${ }^{16}$ do papel do inspetor e da inspeção. Uma representação que coadunava com o que circulava e era efetivado na função em outras províncias: uma inspeção que fiscalizava toda a estrutura da instrução pública - professores, alunos, espaços, materiais, livros de registro - e que emitia seus pareceres, indicando sanções. No entanto, as práticas dos inspetores produziam sentidos para a própria constituição da inspeção. Muitos dos indivíduos que exerciam a função de inspetores estavam envolvidos com as questões e debates sobre a instrução pública em outros espaços, fora da Inspetoria Geral da Instrução: frequentavam associações e clubes literários e lá discutiam e promoviam a instrução; fundavam sociedades, como a que fez Vicente Machado, para a efetivação do ensino obrigatório, em Ponta Grossa, entre outros. Os inspetores não serviam apenas como ferramentas de fiscalização do governo, mas eles estavam inseridos em uma rede de debate sobre a instrução pública e, talvez por causa disso, tinham muitas vezes uma postura de auxílio aos docentes ou de compreensão com as demandas e faltas que os professores tantas vezes apontavam.

Por fim, pode-se indicar que a inspeção paranaense teve sua estrutura modificada ao longo do período, porém, o delineamento de cargos e funções novos não acarretava, necessariamente, a dispensa dos inspetores que até então estavam na função. Muitos deles eram desviados para nova função dentro da inspeção, o que indica ou uma dificuldade de se conseguir pessoas qualificadas para o cargo ou um aproveitamento daqueles que já conheciam o modus operandi da inspeção paranaense e que, por ter essa

\footnotetext{
${ }^{15}$ Sobre atuação da inspeção da instrução pública ver trabalhos de: Barra, 2004; Borges, 2008; Giglio, 2006; Gonçalves, 2004; Marcílio, 2006; Neves, 2009; Oliveira, 2005; Pauferro, 2010; Barbosa, 2012.

${ }^{16}$ Conforme define Roger Chartier, as representações são "esquemas intelectuais incorporados que criam figuras graças às quais o presente pode adquirir sentido, o outro tornar-se inteligível e o espaço ser decifrado" (CHARTIER, 2002, p. 17). Com base nessas representações do mundo social - que são sempre coletivas, embora às vezes partilhadas somente por um grupo ou classe e não necessariamente por toda uma sociedade -, são realizadas, por meio das práticas individuais que as efetivam, diferentes apropriações, isto é, processos singulares por meio dos quais "é historicamente produzido um sentido e diferenciadamente construída uma significação" (CHARTIER, 2002, p. 24).
} 
compreensão, poderia contribuir para a efetivação das novas propostas que estavam sendo indicadas, como a da criação das Superintendências do Ensino Obrigatório.

\section{Referências}

BARBOSA, Etienne Baldez Louzada. Uma teia de ações no processo de organização da inspeção do ensino no Paraná. 2012. Dissertação (Mestrado em Educação) - Universidade Federal do Paraná, Curitiba, 2012.

BARRA, Valdeniza Maria Lopes da. Serviço de inspeção da instrução pública na província paulista (1827-1851). Guanicuns. Rev. Faculdade de Educação e Ciências Humanas Anicuns. Goiás: FECHA/FEA, n. 01, p. 171-187, 2004.

BARRA, Valdeniza Maria Lopes da. O Serviço de inspeção escolar paulista e a gestão da "falta" de professores (1885-1889). In: Anais do VI Encontro Luso-brasileiro de História da Educação. Uberlândia, MG 2006.

BELLO, Luiz Alves de Oliveira. Relatório apresentado à Brazílio Augusto Machado de Oliveira, em 22/08/1884. Curityba: Typ. Perseverança J. F. Pinheiro, 1884.

BORGES, Angélica. Ordem no ensino: a inspeção de professores primários na capital do Império Brasileiro (1854-1855). 2008. Dissertação (Mestrado em Educação) - Universidade Estadual do Rio de Janeiro, Rio de Janeiro, 2008.

BORGES, Angélica. Uma inspeção “inteligente, regular e ativa”: reflexões em torno da fiscalização de professores primários na Corte (1854-1865). In: Anais da $32^{\mathrm{a}}$ Reunião da Anped. Caxambu, MG: Anped, 2009.

CASTANHA, André Paulo. O Ato Adicional de 1834 na história da educação brasileira. Revista Brasileira de História da Educação, n 11, jan./jun. 2006.

CHARTIER, Roger. A história cultural: entre práticas e representações. Lisboa: Difel, 2002.

CHEFE da Superintendência de Curitiba, João Pereira Lagos, convoca superintendentes para a reunião. O Dezenove de Dezembro, 20/01/1884, p. 03.

CIRCUNSCRIÇÃO do Ensino Obrigatório em Ponta Grossa. O Dezenove de Dezembro, 05/02/1884, p. 03.

CONVOCAÇÃO de superintendentes do ensino obrigatório para reunião e notícias sobre as superintendências. O Dezenove de Dezembro, 13/12/1884, p. 01.

DECRETO proposto por Generoso Marques dos Santos. O Dezenove de Dezembro, 29/10/1885, p. 02.

FOUCAULT, Michel. Vigiar e punir: nascimento da prisão. Petrópolis: Vozes, 2008. 
GIGLIO, Célia Maria Benedicto. A civilização pelo olhar: práticas e discursos da inspeção na província de São Paulo no século XIX. In: PINTASSILGO, Joaquim et. al. História da escola em Portugal: circulação e apropriação de modelos culturais. Edições Colibri: Lisboa, 2006, p. 347-364.

GONÇALVES, Rosemeri Conti. Inspeção escolar, civilidade e progresso. In: Anais da $\mathbf{2 7} 7^{\mathrm{a}}$ Reunião da Anped. Caxambu, MG: Anped, 2004.

GRUZINSKI, Serge. A colonização do imaginário: sociedades indígenas e ocidentalização no México espanhol. Séculos XVI-XVIII. São Paulo: Companhia das Letras, 2003.

MARCÍLIO, Elaine Cristina. A ação da Inspetoria Geral da Instrução Pública na Província de Santa Catarina no período de 1874 a 1888: a precariedade da inspeção escolar como instrumento para a uniformização do ensino. 2006. Dissertação (Mestrado em Educação) - Universidade Federal de Santa Catarina, Florianópolis, 2006.

MARCÍLIO, Maria Luiza. História da escola em São Paulo e no Brasil. São Paulo: Imprensa Oficial do Estado de São Paulo: Instituto Fernand Braudel, 2005.

MUNHOZ, Fabiana Garcia. Experiência docente no século XIX: Trajetória de professores

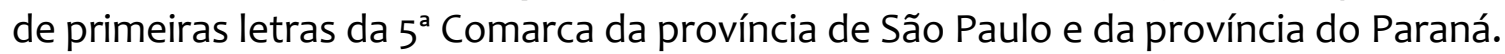
2012. Dissertação (Mestrado em Educação) - USP, Faculdade de Educação, São Paulo, 2012.

NEVES, Dimas Santana Souza. Razões de Estado: as reformas da instituição pública em Mato Grosso, Minas Gerais e Corte Imperial (1851-1859). 2009. Tese (Doutorado em Educação) - UERJ, Faculdade de Educação, 2009.

NICOLAS, Maria. Cem anos de vida parlamentar. Deputados provinciais e estaduais do Paraná. Assembleia Legislativa e Constituintes (1854-1954). Curitiba: Assembleia Legislativa do Estado do Paraná, 1954.

NOMEAÇÃO de Vicente Machado para Superintendente do Ensino Público. Sete de Março, 24/05/1890, p.04.

NOTÍCIAS. Supressão do cargo de Superintendente do Ensino, O Guarany, 04/03/1891, p. 03. (BN)

OLIVEIRA, Maria Cecília Marins. Fiscalização e controle nas escolas do Paraná Província: origem, organização e processo de desenvolvimento. Anais do $2^{\circ}$ Seminário Nacional Estado e Políticas Sociais no Brasil. Cascavel: Unioeste, 13 a 15 de outubro, 2005.

PARANÁ. Regulamento para o Ensino Obrigatório da Província, de 06 de julho de 1877. Coleção de Documentos da Educação Brasileira. In: MIGUEL, Maria Elisabeth Blanck; MARTIN, Sonia Dorotea (Orgs). Coletânea da Documentação Paranaense no período de 1854 a 1889 (CDPR). Brasília: Instituto Nacional de Estudos e Pesquisas Educacionais Anísio Teixeira, 2004. 
PARANÁ. Regulamento de Inspeção da Instrução Pública da Província do Paraná, de 24 de abril de 1857. Coleção de Documentos da Educação Brasileira. In: MIGUEL, Maria Elisabeth Blanck; MARTIN, Sonia Dorotea (Orgs). Coletânea da Documentação Paranaense no período de 1854 a 1889 (CDPR). Brasília: Instituto Nacional de Estudos e Pesquisas Educacionais Anísio Teixeira, 2004.

PARANÁ. Regulamento do Ensino Obrigatório, de 03 de dezembro de 1883. Coleção de Documentos da Educação Brasileira. In: MIGUEL, Maria Elisabeth Blanck; MARTIN, Sonia Dorotea (Orgs). Coletânea da Documentação Paranaense no período de 1854 a 1889 (CDPR). Brasília: Instituto Nacional de Estudos e Pesquisas Educacionais Anísio Teixeira, 2004.

PARANÁ. Regulamento, de 31 de outubro de 1889. Coleção de Documentos da Educação Brasileira. In: MIGUEL, Maria Elisabeth Blanck; MARTIN, Sonia Dorotea (Orgs). Coletânea da Documentação Paranaense no período de 1854 a 1889 (CDPR). Brasília: Instituto Nacional de Estudos e Pesquisas Educacionais Anísio Teixeira, 2004.

PARANÁ. Regulamento do Ensino Obrigatório, 14/05/1891. In: Actos e Leis de 1890, 1891 e 1892 do Estado do Paraná. Curityba: Typ. de A Republica, 1929.

PARANAENSES recebem o grau Imperial da Ordem da Rosa. O Dezenove de Dezembro, 25/09/1884, p. 02.

PASTRE, Marcelo. Clube Curitibano: representações de lazer na formação da sociedade curitibana. 2009. Tese (Doutorado em Educação) - Universidade Metodista de Piracicaba, Piracicaba, 2009.

PAUFERRO, Nezilda do Nascimento Silva. As matrizes históricas da inspeção escolar no Brasil: mecanismo de controle do trabalho docente em Alagoas (1840-1889). 2010. Dissertação (Mestrado em Educação) - Universidade Federal de Alagoas Maceió, 2010.

REGULAMENTO da Instrução Pública do Paraná, 1890. Jornal A República, 31/01/1890.

RELATÓRIO da Sociedade Protetora do Ensino Obrigatório, de Ponta Grossa. O Dezenove de Dezembro, 22/04/1884, p. 02.

REUNIÃO dos amigos de Vicente Machado, na tipografia do referido jornal, para comemoração de sua nomeação como Superintendente do Ensino Público. A República, 25/09/1890, p. 03. (BN)

SÃO PAULO. Regulamento de Instrução Pública da Província de São Paulo, de 08/11/1851. In: COLEÇÃo Leis Provinciais de São Paulo (1844-1849). São Paulo: FFCHL-USP, 1851.

SÃO PAULO. Lei n ${ }^{\circ} 310$ de 16 de março de 1846 (Lei n 34 de 16 de março de 1846). In: COLEÇÃO Leis Provinciais de São Paulo (1844-1849). São Paulo: FFCHL-USP, 1846.

SILVA, Camila Borges da. As comendas honoríficas e a construção do Estado Imperial (1822-1831). In: SIMPÓSIO NACIONAL DE HISTÓRIA (ANPUH), XXVI, São Paulo, julho de 
2011. Anais do XXVI Simpósio Nacional de História - ANPUH • São Paulo: ANPUH, julho 2011.

SUBRAHMANYAM, Sanjay. Impérios em concorrência: histórias conectadas nos séculos XVI e XVII. Lisboa: Imprensa das Ciências Sociais, 2012.

THOMPSON, Edward Palmer. A formação da classe operária inglesa. São Paulo: Paz e Terra, 2004.

VEYNE, Paul Marie. Como se escreve a história e Foucault revoluciona a história. Trad. de Alda Baltar e Maria Auxiliadora Kneip. $4^{\mathrm{a}}$ ed. Brasília: Editora Universidade de Brasília, 1998. 285 p.

VICENTE Machado como professor do Instituto Paranaense. O Dezenove de Dezembro, 28/06/1882, p. 03.

VICENTE Machado como presidente da Sociedade Protetora do Ensino Obrigatório, de Ponta Grossa. O Dezenove de Dezembro, 17/02/1884, p.01.

WACHOWICZ, Ruy Christovam. História do Paraná. Ponta Grossa: Editora UEPG, 2010.

Universidade do Estado de Santa Catarina - UDESC

Programa de Pós-Graduação em Educação - PPGE

Revista Linhas

Volume 18 - Número 36 - Ano 2017

revistalinhas@gmail.com 